\title{
Cuerpo propio y cuerpo ajeno: Sobre la intersubjetividad en Husserl
}

\section{My Own Body and the Other's Body: \\ On Husserl's Intersubjectivity}

DOI:10.12957/ek.2019.44153

Dndo. Pedro Natán Tenner

pedro_tenner@hotmail.com

Universidad de Buenos Aires, Argentina

En el presente trabajo ensayaremos una respuesta a ciertas críticas a la fenomenología de Husserl planteadas por Sartre, para quien la intersubjetividad que describe el autor alemán se funda en una concepción del otro que lo reduce a una categoría suplementaria del conocimiento. Intentaremos demostrar que el lugar central que tiene el cuerpo en la intersubjetividad husserliana abre un horizonte mucho más amplio que el de las posibilidades del conocimiento objetivo. Para ello, nos remitiremos a la quinta de las Meditaciones cartesianas, para luego apuntalar ciertos ejes conceptuales con temas desarrollados en textos de la Husserliana relativos a la intersubjetividad.

\section{PALABRAS-CLAVE}

Fenomenología. Intersubjetividad.

Cuerpo. Alteridad. Empatía

In this article we will attempt response to some of Sartre's criticisms of Husserl's phenomenology. For the French author, intersubjectivity as described by Husserl, is founded on a conception of the other that reduces him to a supplementary category of knowledge. We will attempt to demonstrate that the key role played by the body in Husserl's intersubjectivity opens a much wider horizon than that of the possibility of mere objective knowledge. To do this, we will turn to the fifth of the Cartesian Meditations, to then reinforce certain core concepts by means of themes developed in texts of the Husserliana that address intersubjectivity. 


\section{Introducción}

Una de las principales objeciones que ha recibido la fenomenología ha sido la de recaer en un supuesto solipsismo. Según esta crítica, el método fenomenológico, fundamentado en la explicitación de los contenidos yoicos, describiría un ego encerrado sobre sí mismo que no puede dar cuenta de los otros más que como representaciones en su esfera primordial. El propio Husserl reconoció la aparente validez de estas críticas y dedicó la quinta de las Meditaciones cartesianas a responderlas. En ese texto, Husserl $(1998,152)$ señala que el problema de la empatía o Einfühlung "co-fundamenta también una teoría trascendental del mundo objetivo". En efecto, el sentido de la existencia del mundo, en tanto que mundo objetivo, supone la posibilidad y concreción de una intersubjetividad, puesto que la objetividad implica precisamente que el mundo es uno y el mismo para una multiplicidad de sujetos. El argumento de Husserl se basa en un desplazamiento del eje que determina las condiciones de la objetividad, condiciones que Kant había colocado en el aparato categorial que ordena la intuición subjetiva. Husserl acepta los lineamientos generales de la Estética transcendental kantiana (en tanto que propone un a priori noemático de la intuición sensible), pero sostiene que la constitución de la objetividad por sobre la capa primordial intuitiva no queda explicada por la Analítica transcendental: "La teoría de la experiencia del otro pertenece al primer piso que se levanta sobre nuestra 'estética trascendental"' (Husserl, 1998, 216). Para Husserl, la experiencia de un mundo de objetos no puede depender puramente del aparato cognitivo de un único sujeto de experiencia, puesto que la objetividad del mundo depende del hecho de que, al menos en parte, me es externo y extraño. Tales cualidades podrá poseerlas el mundo de la experiencia únicamente si se constituye a partir de la intersubjetividad: "la alteridad del otro se transfiere al mundo entero como su 'objetividad' y es lo que le da su sentido de tal mundo objetivo" (Husserl, 1998, 216). El sentido de "objetivo" entonces se fundamentará en que los objetos del mundo poseen modos de aparición que me son extraños y que pertenecen a la esfera primordial del otro.

Lo extraño en mi propia esfera primordial determina la objetividad y por ende la posibilidad misma de un mundo a experimentar. Sin el otro, el mundo no tendría su sentido de "objetivo". Éste sería, a grandes rasgos, el resultado del análisis estático que Husserl realiza en la primera parte de la quinta meditación. Parecería que el escollo del solipsismo queda entonces completamente superado. Sin embargo, en su obra El ser y la nada, Sartre renueva la objeción. Allí, el autor concede como acertada la primera consecuencia que se desprende de la po- 
sición de Husserl: "como nuestro yo psicofísico es contemporáneo del mundo, forma parte del mundo y cae con el mundo bajo la reducción fenomenológica, el otro aparece como necesario para la constitución misma de ese yo" (Sartre, 1993, 305). Dudar entonces de la existencia del otro implicaría dudar de mi propia existencia en el mundo. Sin embargo, según Sartre el argumento de Husserl se toparía con el problema de la transcendentalidad del otro. En tanto que, según el propio Husserl, el yo transcendental al que remitiría la presencia psicofísica del otro está siempre ausente, resultaría que "el otro sería allí como una categoría suplementaria que permitiría constituir un mundo, no como un ser real existente allende ese mundo" (Sartre, 1993, 306). Así, para Husserl el otro sería apenas el objeto de una intención vacía: "es un conjunto de operaciones de unificación y de constitución de mi experiencia" (Sartre, 1993, 307). La fenomenología de Husserl haría del otro meramente una condición de posibilidad del conocimiento que un sujeto obtiene de un mundo objetivo. De esta forma, la elucidación del sentido del otro no abandonaría nunca el campo de un yo solipsista que no está explicitando sino la posibilidad de su propio conocimiento.

Sin embargo, al desarrollar su objeción, Sartre parece atenerse exclusivamente a los resultados del análisis estático, que ya hemos esbozado, y parece no tomar en cuenta la aproximación genética que Husserl también desarrolla en la quinta meditación. Es precisamente en este análisis genético que Julia Iribarne ha hecho hincapié, en su trabajo La intersubjetividad en Husserl. Según la autora, Husserl "propone otra forma de la primordialidad, de la que está excluida la experiencia del otro hasta el momento en que el cuerpo del otro se presenta" (Iribarne, 1987, 26). Iribarne sostiene que, aunque incompleto, el análisis genético de la quinta meditación profundiza en el sentido del otro más allá del ámbito de las condiciones de posibilidad del conocimiento, y da indicios de que la intersubjetividad es "un hecho último, originariamente funcionante en el ego" (Iribarne, 1987, 26).

Guiados por el estudio de Iribarne, es nuestra intención explorar las consecuencias de este análisis genético, completándolo con lo dicho en algunos textos de la Husserliana. Creemos que la existencia corpórea del otro ocupa un lugar clave en la teoría de la intersubjetividad de Husserl, y que el carácter fundamentalmente corpóreo y espacial que esa teoría reviste ofrece una solución a la objeción de Sartre. Por supuesto, lo acotado de nuestra investigación nos permitirá sólo señalar algunas posibles líneas de estudio desde donde replantear la forma en que Husserl entendía la relación con el otro. Particularmente, intentaremos elucidar dos puntos: si es cierto que para Husserl la constitución de un mundo objetivo depende de un otro meramente categorial y si la experiencia del otro se agota en esa constitución. 


\section{La quinta meditación cartesiana}

En la quinta meditación, Husserl observa que el análisis estático sobre la experiencia del otro fue realizado sobre la base de una distinción entre lo propio y lo extraño. Sin embargo, en esa distinción lo propio fue descrito como lo "no-extraño", caracterización que depende de la noción del otro y la presupone. El autor se propone entonces tomar como punto de partida del análisis genético otro sentido de la esfera de pertenencia del ego. Como señala Iribarne (1987, 59), en esta nueva modalidad de la primordialidad "dejan de aparecer mis vivencias del Otro porque vamos a asistir a su aparición como cuerpo". Husserl insiste en la importancia de que las vivencias del otro me son inaccesibles directamente, y que sólo pueden ser objeto de una apresentación. Sin embargo, para que la apresentación sea posible es necesario que esté ligada a una presentación en el campo de mi primordialidad monádica. Dentro de ese campo primordial sólo mi cuerpo se distingue, con respecto a los demás objetos materiales, como cuerpo vivo. ${ }^{1}$ Sin embargo, el cuerpo del otro entra en mi campo de percepción no sólo con el sentido de un objeto en el espacio más (como un Körper), sino también como un cuerpo vivo, como un Leib. En tanto que sólo mi cuerpo está constituido como organismo, "ese otro cuerpo físico de allí, tiene que poseer este sentido [de cuerpo vivo] por una transferencia aperceptiva a partir de mi cuerpo vivo" (Husserl, 1998, 173).

La motivación que conduce a considerar el cuerpo del otro como un cuerpo vivo consiste en una "apercepción asimilante" que reúne el cuerpo ajeno con el propio. Husserl señala que en su sentido más general, esta asimilación es un hecho cotidiano de nuestra experiencia: "toda apercepción remite intencionalmente a una 'protofundación' en la que se había constituido por vez primera un objeto de sentido semejante" (Husserl, 1998, 174). Así, cualquier objeto que nos encontremos apresentará escorzos bajo la forma de una anticipación de sentido, en tanto que es un objeto análogo a aquél que se constituyó originariamente. Sin embargo, existen para Husserl dos diferencias clave en la asimilación de otro cuerpo vivo. Para empezar, lo apresentado por él (las vivencias del otro) no puede jamás plenificarse en una intuición, o el otro "sería entonces una parte no-independiente de lo propio de mí mismo, y, en fin, él mismo y yo mismo seriamos uno" (Husserl, 1998, 171). La otra diferencia consiste en que “el original de la protofundación es de continuo aquí algo presente de modo

1 En adelante, utilizaremos simplemente el término "cuerpo" con sentido de cuerpo orgánico o viviente. Si es necesario desambiguar utilizaremos "cuerpo vivo" para traducir Leib y "cuerpo físico" para traducir Körper (siguiendo la traducción de Gaos y García-Baro), o recurriremos a los términos alemanes. 
vivo; o sea, que la propia protofundación permanece constantemente realizándose viva" (Husserl, 1998, 175). En efecto, mi cuerpo está siempre conmigo, y deberá estar presente también en toda experiencia del otro, la cual estará signada por un carácter fundamentalmente corpóreo. El cuerpo del otro adquiere su corporalidad (Leiblichkeit) a partir de mi propia corporalidad.

Con esta última particularidad de la asimilación del otro es que está relacionado un hecho que para Husserl $(1998,175)$ es fundamental: "ego y alter ego están dados siempre y necesariamente en 'parificación' originaria”. Es éste el eje fundamental del análisis genético de la intersubjetividad: la parificación (Paarung). Este término designa, según explica Husserl, un fenómeno universal del ámbito transcendental según el cual dos elementos se dan intuitivamente en la unidad de una consciencia. Veremos en un momento que el fenómeno de parificación, que está a la base de la Einfühlung, se resuelve también dentro del ámbito de lo corpóreo y lo espacial.

Husserl $(1998,180)$ continúa con la observación de que en la esfera de mi primordialidad, "mi cuerpo vivo y físico tiene, en tanto que referido a sí mismo, el modo de estar dado del 'aquí' central. Todos las demás cuerpos físicos -y, por lo tanto, el cuerpo del 'otro'- tienen el modo 'alli'”'. A través de la alteración de mis estados kinestésicos se constituye una naturaleza espacial, cuya orientación queda determinada por el lugar central que ocupa mi cuerpo (asiento de las percepciones). Es ésta también la forma en que adquiero consciencia de mi cuerpo como un objeto en el espacio. Husserl señala que modificando mi situación espacial puedo cambiar todo "alli'” en un "aquí", en tanto que en principio mi cuerpo puede ocupar cualquier lugar del espacio. Esto significa que todo objeto en el espacio no es sólo un sistema de fenómenos que resulte de mi situación espacial aquí y ahora, sino también de "aquellos que corresponden de modo totalmente determinado a ese cambio de posición que me traslada allí” (Husserl, 1998, 181).

Así, Husserl se adentra en un punto clave de su teoría de la intersubjetividad. Cuando el cuerpo del otro entra en el campo de mi percepción, si la parificación se cumple deberé aprehenderlo no meramente como un Körper, sino como un $L e i b$ que posee sus propias sensaciones y su propia esfera primordial monádica centrada en él como un "aquí". Esas sensaciones serán aquellas que yo tendría si estuviera ocupando el espacio que él ocupa. Así, el cuerpo del otro cobra un sentido dual y, en cierta medida, contradictorio: es parte de la naturaleza "allí" que rodea mi cuerpo, pero es también un "aquí" hacia el cual la naturaleza también está orientada. Husserl hace hincapié en que este doble sentido del cuerpo del otro no responde a dos "imágenes", por así decirlo, del mismo cuerpo. El 
cuerpo que se me aparece en el modo del allí "es índice del mismo cuerpo físico en el modo 'aquí' como aquel del que el otro tiene experiencia en su esfera monádica" (Husserl, 1998, 181).

Es importante que señalemos un aspecto fundamental: la forma en que la parificación se cumple entre mi cuerpo y el cuerpo del otro no es directa. $\mathrm{La}$ "transmisión" de sentido que se concreta en la parificación es posible gracias a que el cuerpo ajeno remite a otro modo de aparecer de mi cuerpo propio: "evoca reproductivamente otro [modo fenoménico] inmediatamente semejante de entre los fenómenos que pertenecen al sistema constitutivo de mi cuerpo vivo como cuerpo físico en el espacio" (Husserl, 1998, 182). El cuerpo del otro aparece bajo el aspecto que mi propio cuerpo tendría si yo estuviera "allí". En cualquier asociación, señala Husserl, no ocurre que el objeto aprehendido por analogía quede sometido a las mismas estructuras que el objeto original (si fuera así, el cuerpo del otro sería simplemente una copia de mi cuerpo y el otro no sería otro). Más bien, ambos objetos adquieren el sentido que la parificación, en tanto es un único sistema, les confiere: "Todo traspaso a distancia que tiene su origen en una parificación asociativa es, a un tiempo, fusión y [...] asimilación, igualación del sentido de lo uno al de lo otro" (Husserl, 1998, 183).

Aquí es donde entra en escena la Einfühlung o empatía. Este concepto permite a Husserl describir una suerte de "intercambio de posiciones". Si bien en mi esfera primordial mi cuerpo es incompatible con cualquier modo que no sea el del "aquí,, la confrontación con el cuerpo ajeno ("allí)") permite superar la incompatibilidad. El cuerpo "allí" del otro se me aparece "como si yo estuviera allí", es decir, como el "aquí" que yo poseería si yo mismo estuviera allí. La empatía me permite comprender la naturaleza y sus objetos "allí" como si estuvieran centrados en el cuerpo del otro, con mi propio cuerpo como uno de esos objetos "allí" orientado hacia el "aquí" ajeno. Sin embargo, esta experiencia no puede ser nunca más que apresentada: yo continúo aquí, no estoy allí. De otro modo ambos egos serían uno mismo, y el otro no sería otro. Se da entonces el fenómeno de la co-existencia: dos egos que se reconocen mutuamente como el "aquí" de una esfera primordial que para el otro estará siempre apresentada. La exégesis que Iribarne $(1987,67)$ hace de este pasaje es crucial: el otro "se me presenta gobernando su cuerpo propio como centro de su mundo y como viéndome a mí mismo en ese mundo con los mismos caracteres con que yo lo veo a él”. Veremos cuán importante es para Husserl la conciencia de la subjetividad del otro, y de mi propia subjetividad frente a la del otro.

La parificación y sus apresentaciones hacen que mi "aquí" se me aparezca 
como el "allí" del otro y mi "allí" como el "aquí" del otro. La experiencia apresentada del otro reúne al "yo" y el "tú" en un único sistema fenoménico que se constituye como un "nosotros", como una comunidad. Esta comunidad, que Husserl entiende como una comunidad monádica, será la que permita la constitución de una naturaleza objetiva. Ha de remarcarse el hincapié que Husserl hace en que el cuerpo del otro se aparece a mi percepción inmediatamente como cuerpo vivo dominado por una subjetividad, y no como mero índice de la presencia del otro. El cuerpo del otro no se me aparece entonces como un Körper que fuera imagen de otra primordialidad en la que ese mismo cuerpo tendría el sentido de Leib. Por el contrario, ya en mi primordialidad el cuerpo del otro posee "el sentido de cuerpo vivo ajeno" (Husserl, 1998, 188). Según Husserl el cuerpo del otro apresenta la actividad que un ego realiza en ese cuerpo y, a través de él, en la naturaleza, pero en una naturaleza que es la misma a la que mi propio cuerpo pertenece. Sólo se opera un cambio de orientación: "Es la misma naturaleza, solo que en el modo fenoménico 'como si estuviera allí yo, en el lugar del cuerpo físico-vivo ajeno'” (Husserl, 1998, 188). Así, la naturaleza objetiva se constituye como un entrecruzamiento de orientaciones, como "idéntica respecto de las más ricas multiplicidades que [...] pertenecen a cada orientación singular de aquí y de allí" (Husserl, 1998, 188). La posibilidad de la constitución de esta naturaleza objetiva responde a que la intencionalidad de mi percepción trasciende lo que me es propio: mi ego constituye en su mónada un otro que existe como sujeto del mismo mundo del que yo soy sujeto. Si el cuerpo del otro puede cobrar el sentido de un "aquí" hacia el cual está orientada la naturaleza, es porque apresenta una subjetividad a partir de la presentación de un cuerpo que es efectivamente el cuerpo de otro.

La Einfühlung permite entonces realizar una síntesis entre mi esfera de pertenencia primordial y la de la subjetividad que el cuerpo del otro me apresenta. De esta manera puede tenderse un puente intencional entre aquello que debe permanecer completamente ajeno entre sí. Husserl insiste en que el primer momento de este puente es la co-existencia en una misma naturaleza de dos cuerpos que se reconocen mutuamente como cuerpos orgánicos y por lo tanto como apresentando una vida subjetiva. Una vez realizada la síntesis que identifica los dos modos de aparecer de esos cuerpos ("aquí" y "allí") es que podemos considerar que se sintetizan las representaciones de la naturaleza en una misma naturaleza idéntica y objetiva. Naturaleza, además, en la que a partir de entonces ambos cuerpos se encuentran inexorablemente el uno junto al otro. Husserl sin embargo no se detiene allí, sino que agrega un aspecto aún más fundamental de esta comunidad intencional: "gracias a ello queda protofundada la coexistencia 
de mi yo (y, en general, de mi ego concreto) y el yo ajeno, de mi vida intencional y la suya, de mis 'realidades' y las de él; en una palabra: una forma temporal común” (Husserl, 1998, 194).

Hasta aquí los lineamientos generales del análisis genético de la intersubjetividad según aparece en la quinta meditación. Creemos que varios de los puntos señalados pueden enriquecerse si se complementan con lo dicho en algunos textos de la Husserliana. Antes de pasar a dichos textos, quisiéramos remarcar los puntos en cuestión:

1) La constitución de la naturaleza objetiva no ocurre en relación a un otro meramente categorial o lógico, sino a un alter-ego parificado con el ego. Esta parificación sólo puede darse como apresentada y por medio del reconocimiento de una subjetividad ajena que domina sobre un cuerpo que es Leib y no meramente Körper. El cuerpo del otro se me aparece como un "aquí" ajeno, que apresenta toda otra orientación de la naturaleza. Así, la naturaleza objetiva comienza a aparecer como una superposición de "orientaciones": múltiples "aquí", uno de los cuales me es accesible primordial y originariamente, mientras que los demás me están siempre apresentados. Es por ello que enfatizamos que la teoría de la intersubjetividad reviste un carácter fundamentalmente corpóreo y espacial. Husserl (1998, 190) observa que la génesis de la naturaleza objetiva "atañe en primer lugar al cuerpo físico-vivo ajeno, que es, por así decir, el objeto en si primero". En tanto que el cuerpo del otro adquiere ese sentido sólo en parificación con el mío, se podría decir que la intersubjetividad es en realidad una "intercorporalidad", una suerte de resonancia de cuerpo a cuerpo. De hecho, Husserl $(1998,196)$ describe la naturaleza objetiva como "una multiplicidad abierta" que "comprende en sí a un número no conocido de hombres [...] que se reparten por el espacio infinito como sujetos de una posible comunidad mutua".

2) El otro y su extrañeza no se agotan en una mera condición de posibilidad del conocimiento. El fenómeno de la parificación tiene alcances mayores. La transferencia del sentido de "aquí" hacia el cuerpo del otro depende de que el otro se me aparezca como sujeto del mundo que lo rodea, incluyéndome a mi cuerpo en ese mundo. Iribarne señala que experimento al otro como objeto del mundo, pero "también lo experimento como experimentando a su vez ese 
mundo y a mí mismo dentro de él, o sea lo experimento como sujeto para ese mundo" (Iribarne, 1987, 196-7). De allí surge el fenómeno de la constitución mutua, que Husserl describe del siguiente modo: si estoy frente al cuerpo del otro "así como su cuerpo físico-vivo se encuentra en mi campo perceptivo, así también el mío en el suyo; él tiene, en rasgos generales, experiencia de $m i ́$ sin más como otro para él, del mismo modo que yo tengo experiencia de él como mi otro" (Husserl, 1998, 196). La posibilidad de la experiencia "como si yo estuviera allí" implica que a lo que me enfrento de manera apresentativa es a la subjetividad del otro. Asimismo, reconozco que la subjetividad ajena apresenta la mía propia. En el mutuo reconocimiento de nuestras subjetividades, el otro aparece como algo de mucho más "peso" que una mera condición de posibilidad de la objetividad. La subjetividad que, por así decirlo, está “detrás” del cuerpo del otro es un hecho al que me enfrento y que será determinante en mi propia constitución. De hecho, algunos parágrafos más adelante Husserl dirá que "el factum 'yo soy” prescribe si hay mónadas que sean para mí otras y cuáles otras lo son. Yo no puedo más que encontrarlas, pero no puedo crear a las que ha de haber para mí" (Husserl, 1998, 209). Mi existencia como ego es en realidad una co-existencia frente a una cierta multiplicidad de mónadas ajenas. Soy quien soy en relación con los otros con los que co-existo.

3) Si bien es cierto que la primordialidad ajena se me aparece como siempre ausente, debe considerarse que tal ausencia es condición de la parificación entre ego y alter-ego, puesto que en toda parificación es necesario que los elementos aparezcan como distintos, a pesar de quedar incluidos bajo una misma conciencia. Si la subjetividad ajena estuviera presente en mi primordialidad el cuerpo del otro sería simplemente una "copia" de mi propio cuerpo, dominado por mi propia subjetividad. La ausencia del otro se da entonces bajo la forma de la co-existencia, es decir, como un modo de la presencia. La co-existencia y co-presencia de dos egos que se reconocen mutuamente depende del hecho de que a nivel primordial uno esté ausente al otro. El otro está frente a mí (y yo estoy frente a él) precisamente no estando. Así, tampoco este modo de la ausencia del otro autoriza a hablar del otro como una mera condición de posibilidad o categoría vacía. Husserl $(1998,195)$ habla de la forma en 
que el otro está frente a mí en la parificación como "de un tipo de enlace peculiar por principio, de una verdadera comunidad".

4) El fenómeno de la constitución mutua y la comunidad monádica que resulta de él sirven de indicio de consideraciones genéticas de mayor profundidad. Husserl $(1998,194)$ señala que "la comunidad temporal de las mónadas referidas constitutivamente las una a las otras es indisoluble porque está en nexo esencial con la constitución de un mundo y de un tiempo del mundo". La forma temporal común en que se reúnen todas las mónadas indica un entretejimiento de intencionalidades que el autor no deja de remarcar. Husserl observa que toda mónada está inexorablemente separada de todas las otras, y que a esa separación corresponde en el mundo una "brecha" que se presenta como espacial. Sin embargo, la comunidad original no puede negarse. El autor considera una forma de penetración intencional que califica de "irreal", pero no en el sentido del sueño o la fantasía: "un ser está con otro ser en comunidad intencional” (Husserl, 1998, 195). Esta comunión se encuentra a la base de toda sociedad humana: "conforme a la esencia que tiene las fuentes de su necesidad en el ego trascendental y, luego, en la intersubjetividad trascendente que se abre en él" (Husserl, 1998, 203). Los cuerpos distribuidos en el espacio están inexorablemente separados, pero se constituyen mutuamente con un sentido de Leiber y no solamente de Körper. De esa forma, apresentan una comunión intencional y original en la que las primordialidades penetran la una en la otra. Podría decirse entonces que el cuerpo del otro es una ventana hacia el exterior de mi mónada.

\section{Plenificación en la experiencia del otro}

En su estudio de la quinta meditación, Iribarne dirige al lector a un texto de la Husserliana que quisiéramos examinar primero, puesto que resulta particularmente relevante para nuestro modo de aproximación al tema de la intersubjetividad. Se trata del Anexo LVI al texto 16 del tomo XIII. Allí Husserl se preocupa por distinguir dos maneras de percepción del otro, una inauténtica y una auténtica. Citamos la distinción que Husserl (1973, XIII, 479) hace: 
1) la percepción inauténtica, que comprende vacíamente, la apresentación vacía del otro [...] por la cual el mero cuerpo [Körper] realmente está dado según la percepción, y no como cuerpo vivo [Leib]. 2) La percepción real del otro como otro, es decir, la apresentación plenificada, plenificada por medio del contexto de motivaciones realmente viviente. ${ }^{2}$

La posibilidad de plenificación de la primordialidad ajena no va en contra de lo dicho en la quinta meditación. Por el contrario, se desprende de la forma en que en ese texto se entiende la constitución objetiva del mundo. En este anexo, Husserl (1973, XIII, 478) explora nuevamente la relación de los cuerpos orgánicos en el espacio como una suerte de intercambio de posiciones. El autor señala que la percepción apropiada del otro "me implica como casi viviendo allí [quasi dort Lebenden], experimentando desde allí”. Siempre que la percepción no sea una mera indicación vacía, el otro se me aparece como un "aquí" hacia el cual mi cuerpo está orientado, en el modo del "allí". Pero un "allí" que experimenta, y que se experimenta a sí mismo como un "aquí", para el cual el otro existe en el modo del "allí". Vemos en esta elucidación de la experiencia de lo extraño nuevamente el fenómeno de la constitución mutua y el juego de espejos que parece implicar: yo constituyo al otro como constituyéndome, pero constituyéndome como alguien que lo constituye. Resaltamos nuevamente que este mutuo reconocimiento como sujetos del mundo se resuelve, con determinaciones fundamentalmente espaciales, en una transferencia de sentido de Leib al Körper ajeno. En tanto que lo que hace Leib a un Körper es precisamente su carácter de "punto cero" para una subjetividad, es que puedo tener en la experiencia del cuerpo del otro una plenificación de esa subjetividad. El cuerpo del otro puede ser Leib y "aquí" sólo si reconozco que sobre él domina un sujeto. El hecho de que frente a él me reconozco como un "allí" (además de como el "aquí" que siempre seré) basta para entender la presencia del otro como plenificada. Esta plenificación responde necesariamente a la ausencia de su primordialidad, puesto que ésta es condición de posibilidad del carácter de "aquí" del cuerpo ajeno, precisamente en tanto ajeno. Sin esa ausencia, el cuerpo ajeno o no sería un Leib "aquí" (sería un mero Körper pues no apresentaría una subjetividad), o sería un "aquí" del que yo sería consciente mediante presentación y no apresentación: el otro sería efectivamente yo mismo. La conciencia de esa ausencia plenifica lo implenificable. Husserl (1973, XIII, 478-9) habla de esta

2 Las traducciones de los textos de la Husserliana son nuestras, salvo la del texto titulado "Una conversación nocturna", traducido por Iribarne. 
plenificiación diciendo que la experiencia del otro "debe volverse intuitivamente viva para mí, como transición del Aquí en el Allí, de mi dadidad de orientación [Orienterungsgegebenheit] en la del Allí y como existencia intuitivamente plenificada del otro, que se co-fundamenta en este 'como sí', como un poner una co-presencia junto a la mía".

La constitución de una naturaleza objetiva se resuelve entonces en este "intercambio de posiciones", que a su vez sólo puede existir frente a un otro co-presente en el mundo conmigo. Si el otro no está co-presente, la percepción de lo ajeno será inauténtica y por ende vacía: el Körper del otro no tomará el sentido de Leib. Si concordamos con Husserl, podemos ver ya aquí una posible respuesta a la crítica sartriana. Aún si nos concentramos únicamente en la importancia del otro como condición de posibilidad del conocimiento objetivo, ese otro es mucho más que una mera categoría vacía. Vemos que el propio Husserl se preocupa de dar cuenta de una posible comprensión del otro como objeto de una intuición vacía, y dedica algunas páginas a distanciarse de esa posición. Sin embargo, se podría argumentar que en tanto se trata todavía de la constitución de una naturaleza objetiva, la co-presencia del otro depende de cuán certera es mi propia experiencia del mundo como objetivo. En última instancia, parecería que al dar cuenta del otro nuevamente no hago más que elucidar la posibilidad del conocimiento teórico que yo poseo del mundo. Sin embargo, como veremos, para Husserl la constitución de un mundo común va más lejos en sus consecuencias.

\section{Mundo sensorial común}

Para continuar nuestro análisis, nos remitimos al tomo XIV de la Husserlia$n a$, particularmente al texto n. 10, titulado Gemeingeist II. Allí, en el contexto del estudio de la vida comunitaria, Husserl regresa sobre el tema de la constitución de un mundo común, no ya sobre la base de su objetividad, sino haciendo hincapié en el aspecto de su sensorialidad. Este ligero desplazamiento del eje de la objetividad a la sensorialidad resalta aún más el carácter corporal de la constitución del mundo común. El autor señala de hecho que este mundo puede constituirse sólo en tanto que cada sujeto tiene consciencia de existir frente a un número indefinido de sujetos, con los que compartirá una misma Umwelt en el modo del "nosotros". Esta interrelación es entendida como una configuración de cuerpos orgánicos: “cada uno pertenece para cada uno al 'estar en frente'; cada uno tiene su lugar, su localización en el cuerpo vivo del extraño que está en frente" (Husserl, 1973, XIV, 197). Es interesante que Husserl hable de la "loca- 
lización en el cuerpo del extraño". En efecto, una de las definiciones del cuerpo que da la fenomenología es la de campo de localización de las sensaciones. ${ }^{3} \mathrm{La}$ aparición aquí del término nos remite a lo que en el contexto de nuestro análisis de la quinta meditación dimos a llamar "resonancia corporal". Sólo por ocupar un lugar en el espacio, mi cuerpo esta de algún modo localizado en el cuerpo ajeno que este frente a mí, puesto que me recibe en su campo de sensaciones. ${ }^{4}$

Husserl continúa con una tesis fuerte: si existo en comunidad, "experimento no sólo con mis sentidos, sino también con los del otro, y el otro experimenta no sólo con los suyos, sino también con los míos" (Husserl, 1973, XIV, 197). La constitución de un mundo de los sentidos común depende de la posibilidad de relacionarme con ese mundo a través de los sentidos de los otros, y de los otros a través de los míos. Nuevamente nos encontramos con una configuración corporal y espacial, en la que la transmisión de sentido de "aquí" a "allí" revela una dimensión más profunda. Mi cuerpo y mi sensibilidad determinan la experiencia que tiene el otro, y lo hace como un "allí" que, en tanto que también es "aquí", le ofrece al otro una nueva capa de comprensión sensorial del mundo. Su cuerpo también, por tanto, apresenta una suerte de extensión de mi propia sensibilidad. ${ }^{5}$ Pero Husserl no se detiene allí, sino que continúa diciendo que este hecho es "está siempre operando para mí, en mi comportamiento, ya en el de la esfera de mi pasividad, mi afección y mi mera recepción” (1973, XIV, 197). El autor asegura que no se trata meramente de la forma en que el mundo cobra sentido objetivo y hace posible por ende el conocimiento teórico. El comportamiento de los cuerpos orgánicos se verá afectado por esta interrelación corporal: la forma misma en que mi cuerpo actúa y se relaciona con el mundo queda determinada por la forma en que los cuerpos de los otros lo hacen. Y viceversa, toda operación corporal en el mundo que yo efectúe tendrá sus conse-

3 Ver Husserl, 2005, 145-6.

4 Por supuesto, el cuerpo del otro está también localizado en mis sensaciones. Veremos que aquí también se da el fenómeno de la constitución mutua.

5 Puede resultar de interés mencionar aquí el tratamiento que Husserl hace de la constitución del cuerpo en Ideas II. En ese texto, Husserl enfatiza el carácter dual que el cuerpo adquiere: es Körper y Leib, cosa material y más que cosa material, etc. Si bien en ese análisis Husserl adopta metodológicamente una posición solipsista, otra de las descripciones del cuerpo que allí realiza parece alcanzar una significación más profunda cuando se la considera en un contexto de intersubjetividad: nos referimos al cuerpo como Mitglied y Gegenglied. Si se transfiere la idea a un contexto de intersubjetividad, no es difícil ver allí un paralelismo con la descripción del cuerpo del otro como "allí" que, en relación con su subjetividad, es también un "aquí". El cuerpo del otro se me aparece a una vez como el Mitglied de la subjetividad ajena y, en tanto que percibo a través de su sensibilidad, como el Gegenglied de mi subjetividad. La constitución mutua transfiere también ese doble sentido a mi propio cuerpo. Quizá podría decirse que aún si se lo considera de manera solipsista, ese carácter dual demuestra que el cuerpo propio "tiende" ya hacia la presencia del cuerpo ajeno, algo que, como veremos en la última sección, es fundamental. Ver Husserl, 2005, 157. 
cuencias en la sensibilidad de los otros. Este fenómeno está además “operando constantemente" [beständig wirksam], puesto que nuevamente la sensibilidad del otro deberá afectar a la mía, y así sucesivamente. Nuevamente, se trata de un juego de espejos entre los cuerpos, que incluye su relacionarse con el mundo. Para Husserl el otro me afecta al nivel de la comprensión del mundo, pero no sólo de manera que determine mi comprensión teórica, sino también mi comprensión práctica: la relación del cuerpo del otro con el mío (y viceversa) determina cómo se comportan nuestros cuerpos en ese mundo. Husserl expresa esta idea diciendo que si existimos en comunidad nos dirigimos hacia "nuestra" experiencia, no cada uno únicamente hacia la suya propia.

De allí entonces que no podamos concordar con la crítica sartriana: lo ajeno y la alteridad no se justifican en Husserl meramente por el hecho de mi conocimiento objetivo del mundo. Cuando explicito la experiencia del otro, describo más que la forma en que su "punto de vista" me permite entender el mundo a mi alrededor. Describo también la forma en que su existencia corpórea determina la mía, la forma en que su comportamiento corpóreo determina el mío (y viceversa). Todo lo cual implica necesariamente una descripción de la co-existencia (o presencia en la ausencia) de la subjetividad ajena como dominando sobre el cuerpo ajeno. El entrelazamiento de primordialidades se resuelve en el campo de una resonancia corporal, de un orientarse los cuerpos los unos a los otros. Lo cual sólo es posible en relación con una subjetividad ajena de la que soy plenamente consciente, si bien de un modo particular y único en su género.

Por otro lado, la constitución de un mundo de los sentidos común actúa para Husserl como indicio de una capa más profunda a la que la fenomenología genética puede acceder, si bien el autor no se ocupa de ella en este texto. En efecto, Husserl (1973, XIV , 197) nuevamente enfatiza que somos una multiplicidad de sujetos de experiencia, pero que, en tanto existimos en comunidad "cada uno se beneficia de todos los sentidos, y de tal manera que cada uno [...] se sabe frente a un mundo idéntico, como el mismo para todos". De esta forma, a pesar de la multiplicidad de subjetividades, la existencia en comunidad es "como si hubiera un único sujeto como correlato de este mundo común” (Husserl, 1973, XIV, 197). Todas estas consideraciones, que ya estaban delineadas en la quinta meditación, encuentran su continuación y su sentido más profundo en el último texto que examinaremos. Se trata del texto 33 del tomo XVI, "Una conversación nocturna" ("Ein Nachtgespräch"). 


\section{Presente viviente}

En el texto mencionado, Husserl comienza por recapitular las consideraciones acerca de una naturaleza común constituida a partir de una pluralidad de cuerpos orgánicos localizados en el espacio. Lo interesante del análisis es el énfasis que Husserl pone en la forma en que las relaciones corporales se reflejan en la intercomunicación intencional de las primordialidades: "en virtud de la Einfühlung y de la validez de ser [Seinsgeltung] que la recorre, cada una de mis kinestesias condiciona actividades, las de todos los otros yo, con sus primordialidades" (Husserl, 1987, 353). Según el autor, toda actividad, ya sea una mera percepción pasiva o un accionar, trae aparejada alguna alteración de mi cuerpo, pero en tanto que éste existe en relación a otros cuerpos, los cuerpos ajenos se verán alterados conforme se altere el mío (como siempre, la relación en la dirección contraria es también válida). Así, podemos decir que cada alteración "alcanza el interior [hineingreifen] de cada primordialidad ajena que valga para mí", puesto que "cada cambio de mi cuerpo propio primordial está ahí para cualquier otro" (Husserl, 1987, 353).

El autor insiste en la constitución de la naturaleza a partir de la sensibilidad ajena, centrando el análisis aún más en el aspecto corporal. En efecto, Husserl observa que la existencia sensorial de cada sujeto es un "estar localizado" en la naturaleza mediante su cuerpo, percibiéndola y alterándola según las capacidades motrices de ese cuerpo. La Einfühlung se concreta en el hecho de que "el cuerpo propio de todo otro es para cada uno como cuerpo externo [Aussenkörper] ahí, y en su movilidad corporal [leiblich] propia y no alterada" (Husserl, 1987, 354). Es precisamente la motricidad del cuerpo del otro lo que constituye la naturaleza común en la que los sujetos están localizados. De esta manera, la naturaleza sólo puede tener la forma que los cuerpos de la multiplicidad indefinida de sujetos puedan percibir o producir mediante sus kinestesias. Nuevamente, la naturaleza común se caracteriza como una armonía y un entrecruzamiento de orientaciones: "Todo acontecimiento natural, todo movimiento en la naturaleza se me presenta a mí y a cada uno como orientado y en posibles cambios de orientación" (Husserl, 1987, 354).

Sin embargo, Husserl $(1987,355)$ señala que el mundo aparece siempre fundamentado por una capa de carácter pre-dado: la coincidencia constitutiva funda una naturaleza que "se presenta como la misma a cada yo primordial en pre-dadidad [Vorgegebenheit] orientada". Este mundo pre-dado es un mundo orientado hacia los cuerpos orgánicos en el espacio, los cuerpos de sujetos que están localizados en la naturaleza. El mundo pre-dado implica de por sí una multiplicidad de cuerpos orgánicos (es decir, de cuerpos que apresentan subje- 
tividades) a quienes estará dado. Por lo tanto, en la constitución de la naturaleza común es necesario que yo entienda al otro "de inmediato" [vom vornherein] como otro yo (Husserl, 1987, 355).

Husserl observa una relación entre la experiencia del ego de su propio pasado y la experiencia "de inmediato" del alter-ego como un ego. Para elucidar ambas experiencias, el autor propone una nueva reducción que denomina "la reducción final". Esta reducción deberá revelarme mi presente transcendental, en el que "está implícito mi pasado transcendental [...] con mi "mundo" cada vez correlativamente constituido" (Husserl, 1987, 357). Este mundo incluirá también por supuesto la existencia de los otros y mi propia existencia mundana: será en efecto el mundo pre-dado de las subjetividades localizadas por medio de sus cuerpos. De esa manera, podríamos hablar de una suerte de movimiento circular en la secuencia de reducciones que hemos analizado. En la quinta meditación Husserl llevó a cabo una epokhé que eliminaba todo rastro del otro mundano, para poder asistir a su aparición en mi primordialidad. La fenomenología genética dio cuenta de la constitución del sentido del otro y de las consecuencias que se desprenden de él. Ahora debemos regresar a aquella reducción, pero incluyendo las conclusiones que han arrojado las consideraciones genéticas. Esta nueva reducción revela que mi existencia en el mundo junto a los otros es el resultado de una estructuralización en pasado, presente y futuro a partir de la corriente del tiempo primigenio: "El fluir es proto-temporalización [Urzeitung], y el análisis transcendental es despliegue de las implicaciones, que [...] ocurren como génesis implícita" (Husserl, 1987, 357). La génesis implícita precisamente será la del "mundo predado, mi pasado mundano [...], naturalmente los congéneres [Mitmenschen]" (Husserl, 1987, 357).

Husserl sostiene que esta corriente del tiempo primigenio es una suerte de "yo soy" o "yo hago" primigenio, un ego que recibe esa denominación sólo equívocamente, puesto que aquí no tendría ningún sentido hablar de un alter-ego. A partir de este yo primigenio, previo a la alteridad, es que Husserl $(1987,359)$ explica la posibilidad de un ego que se encuentra como tal frente a la alteridad de los otros y de su propio pasado: "Es el yo, el primigenio de la vida primigenia, que tiene implícito en sí su propio ser como ego frente a los alteri y así tiene implícito en sí el ser según Einfühlung de los Otros”. El nacimiento es una forma de alteración en esta corriente pre-temporal, una temporización y espacialización de la yoidad última, que desde entonces se verá a sí misma como un cuerpo en resonancia con otros cuerpos, por medio de la Einfühlung. ${ }^{6}$

6 La otra forma de alteración a la que se somete ese yo en tanto se ha constituido como psicofísico es la muerte. 
Husserl observa que la monadología que ha propuesto en la quinta meditación cartesiana encuentra su posibilidad precisamente en esta corriente primigenia. Normalmente, este fluir primigenio no es directamente accesible a las operaciones intencionales (puesto que éstas presuponen la articulación en pasado, presente y futuro de la corriente primigenia). Sin embargo, encuentro un índice suyo en la alteridad de mi propia vida pasada y de los otros ego: "É1 lleva en si los egos propios, los que unos respecto de los otros son alteri" (Husserl, 1987, 360). La "imbricación intencional [intentionale Verflochtenheit]" de las primordialidades monádicas (que, si tenemos razón en nuestro análisis, no es más que la comprensión de la Leiblichkeit ajena) sirve de indicio de una capa más profunda, desde donde se originan todas las temporalizaciones y espacializaciones de cada ego. Las apresentaciones "detrás" del cuerpo ajeno (la inexorable ausencia en su presencia) funcionan como una suerte de apertura de mi primordialidad cuando comprendo que los otros también pueden llevar a cabo la reducción que les permita alcanzar su egoidad primigenia. Esta realización trae aparejada la comprensión de una interconexión a nivel primigenio entre las yoidades: “mi ego primigenio implica una 'infinitud' de egos primigenios, cada uno de los cuales implica todo otro y precisamente a partir de sí esta infinitud, entre ellos también mi ego en el que todo eso está implícito, como precisamente éste también otra vez está implícito en cada uno" (Husserl, 1987, 361). En la conversación nocturna que Husserl describe, mi yoidad no es más que el alter-ego de otro ego, que a su vez es alter-ego de un número inagotable de egos, todos los cuales son alter-egos de mi ego. Aquí aparece el sentido último del fenómeno de la constitución mutua, que vimos surgir en todos los niveles de análisis. En este nivel último que nos ha revelado el análisis genético, la pluralidad de yoes y su interconexión aparecen como un factum último, como la estructuralización en tiempo y espacio de una corriente primigenia del presente viviente. En el mundo pre-dado que esta primera "estructuralización" ofrece, ego y alter-ego se entrecruzan, se entremezclan y se significan mutuamente

Como vimos, ya en la quinta meditación Husserl hablaba de la posibilidad de una forma temporal común, resultado de la conexión intencional intermonádica. Asimismo, el autor había señalado la posibilidad de que tal interconexión encontrara sus raíces en los últimos fundamentos transcendentales. Sin embargo, en ocasión de ese texto Husserl no continuó la investigación en esas líneas. Un análisis genético más profundo revela ahora que más allá del tiempo objetivo intermonádico se encuentra la corriente del presente viviente, que es condición de toda temporalización y por ende de la monadología que hace posible el tiempo objetivo. Esta "letzte Reduktion” y sus consecuencias sólo pueden 
alcanzarse de cara a la alteridad. Así, el cuerpo del otro y la relación de mi propio cuerpo con él funcionan como una suerte de ventana para mi mónada, como mi propio cuerpo lo es para la mónada ajena. ${ }^{7}$ Husserl $(1987,361)$ finaliza el análisis genético con las pertinentes palabras: "todos los Otros están en mí en su totalidad de la infinitud, y están en mí como implicando en sí todo existente en todo sentido - allí para mí cada uno tiene igual valor".

\section{Conclusión}

En su estudio, Iribarne observa que aunque Husserl nunca sistematizó su teoría de la intersubjetividad (algo que de hecho habría ido en contra de su aproximación al estudio filosófico), puede descubrirse en tal teoría un carácter distintivamente unitario. De hecho, la fenomenología genética encuentra una continuidad de la interrelación monádica en todos los estratos que estudia, desde el mundano hasta el ámbito último de la transcendentalidad. Como señala Iribarne $(1987,139)$, "la unidad propia de la teoría husserliana de la intersubjetividad se funda en la común pertenencia de todos los estratos explicitados, al ámbito transcendental". El material que la Husserliana provee al respecto de esta teoría es de extensión abrumadora. Nos hemos esforzado por seguir un hilo conductor: el del cuerpo ajeno y el vínculo de mi cuerpo con él, así como las consecuencias que tiene en esta relación los fenómenos de la parificación y la constitución mutua.

La selección de textos y el eje de nuestra aproximación al tema han sido motivados por la crítica sartriana a Husserl, según la cual el filósofo no habría superado el solipsismo. La crítica de Sartre se articula a partir de dos ejes centrales. En primer lugar, en la constitución del mundo objetivo, el otro se me aparece como una ausencia, un vacío meramente categorial. En segundo lugar, la experiencia del otro se limita a la constitución de la objetividad. Hemos visto sin embargo que: 1) incluso si nos concentramos en el rol de la alteridad a la hora de la constitución del mundo objetivo, tal constitución se da en parificación con una sensibilidad y un cuerpo ajenos dominados por una subjetividad. La subjetividad transcendental del otro puede plenificarse de un modo sui generis por medio de la apresentación y la experiencia "como si yo estuviera allí”; 2)

7 Resulta pertinente citar aquí un fragmento de la obra de Roberto Walton Husserl. Mundo, conciencia y temporalidad: "Desde el punto de vista del análisis fenomenológico trascendental, la existencia de múltiples yoes es un factum último [...] El problema transcedental es el de cómo se llega a tener conciencia del factum de la comunidad monádica, y ello sucede precisamente a partir de las experiencias elementales que tienen lugar cuando el cuerpo propio está sujeto a tendencias primitivas orientadas al alter ego" (Walton, 1993, 124). 
Mi existencia corporal está determinada por la existencia corporal del otro (y viceversa). El mundo en común que constituimos es también el mundo en que nuestros cuerpos actúan, con comportamientos que se determinan mutuamente. Las posibilidades de los comportamientos y la motricidad corpóreos configuran la naturaleza. El otro es entonces más que un fundamento teórico: la interconexión intencional de mónadas determina también el aspecto práctico de la existencia humana; 3) También en otro sentido es el cuerpo del otro más que una mera categoría: lo apresentado por la corporalidad ajena sirve de indicio para una profundidad transcendental que es inaccesible de forma directa y que sirve de enraizamiento para la "forma temporal común" de la comunidad monádica.

Si bien estos tres puntos deberían explorarse con mayor detenimiento si es que se pretende refutar a Sartre, creemos que bastan para probar que hay en Husserl al menos el indicio de una teoría de la intersubjetividad que no sólo supera el solipsismo, sino que también ofrece un hilo conductor para un análisis fenomenológico sumamente fructífero.

Recebido em: 13.07.2019 | Aprovado em: 20.08.2019

Husserl (1973), Husserliana [ed. Iso Kern], Tomos XIII, XIV y XV, La Haya: Martinus Nijhoff.

Husserl (2005), Ideas II [trad. Zirión], México DF: FCE.

Husserl (1998), Meditaciones cartesianas [trad. Gaos y García-Baro], México DF: FCE.

Husserl (1987), "Una conversación nocturna” [trad. Iribarne], en Iribarne, La intersubjetividad en Husserl, Tomo II, Buenos Aires: Carlos Lohlé.

\section{Referência Bibliográfica}

Iribarne (1987), La intersubjetividad en Husserl, Tomos I y II, Buenos Aires: Carlos Lohlé.

Sartre (1993), El ser y la nada [trad. Valmar], Buenos Aires: Losada.

Walton (1993), Husserl. Mundo, conciencia y temporalidad, Buenos Aires: Almagesto.

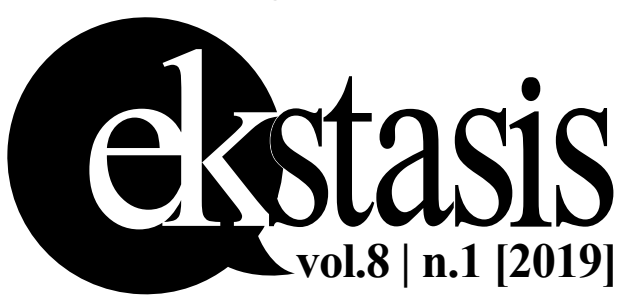

